\section{International Review of Applied Sciences and Engineering}

12 (2021) 1, 29-33

DOI:

$10.1556 / 1848.2020 .00114$

(c) 2020 The Author(s)

\section{ORIGINAL RESEARCH} PAPER

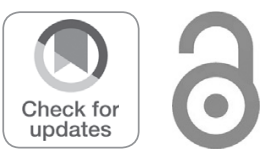

\title{
Soil behaviour under load in case of finite thickness
}

\author{
Nihal D. Salman ${ }^{1,2^{*}} \odot$, György Pillinger ${ }^{1}$ and Péter Kiss ${ }^{1}$ \\ ${ }^{1}$ Mechanical Engineering Doctoral School, Szent István University, 2100 Gödöllő, Hungary \\ ${ }^{2}$ Baquba Technical Institute, Middle Technical University, Baghdad, Iraq
}

Received: February 29, 2020 • Accepted: June 19, 2020

Published online: December 4, 2020

\begin{abstract}
This study intends to examine the soil behaviour in the case of finite thickness, represented by the hard layer under a soft layer of soil. A further aim is to define load-bearing capacity parameters $(n$ and $k$ ). The experimental work is carried out under laboratory conditions by using hydraulic bevameter to apply the load. A circular plate with a diameter of $100 \mathrm{~mm}$ is used to push down the load over the targeted area with a penetration rate of about $9 \mathrm{~cm} / \mathrm{min}$ for sinkage plates. The study was conducted in a soil bin (length of $200 \mathrm{~cm}$, width of $100 \mathrm{~cm}$ and variable thickness) using a sandy loam soil. First, the study has been done with loose soil with a thickness of $11 \mathrm{~cm}$, which maintained with $10 \%$ moisture content and initial density of $1.190 \mathrm{~g} / \mathrm{cm}^{3}$. After that, a two thickness of 6 and $18 \mathrm{~cm}$ with $8 \%$ moisture content and initial soil density of $1.375 \mathrm{~g} / \mathrm{cm}^{3}$ were tested to explain the effect of thickness. In each test, the bevameter plate was loaded at multiple locations, the result showed the soil was near uniform. The result suggests that it is not easy to obtain one equation for the load bearing capacity because the layer near to the surface behaves like soil with infinite thickness and the deeper layer like soil with finite thickness.
\end{abstract}

\section{KEYWORDS}

soil deformation, load bearing capacity, hard layer in a soil

\section{INTRODUCTION}

The distribution hardness of the soil with finite thickness is one of the greatest obstacles to evaluate the experimental result and define the load bearing capacity where the rigid layer of a certain depth changes the pressure distribution. The agricultural soils are tilled to a depth which is comparable with the equivalent contact diameter of tyres. The tillage processes and following settling form considerably various local load carrying capacities at different depths where the soil consists of a soft upper layer and a more resistant and rigid lower layer. The difference between the loose upper layer and the hard layers underneath cause difference in the pressure distribution. A firm layer fundamentally modifies the pressure distribution in the soil body [1].

The strength of the soil is highly dependent on several parameters, one of them is the soil moisture content. In unsaturated soils, soil strength decreases progressively with increasing soil moisture content; the soil bulk density effect on the soil compression behaviour, where the low bulk density soils have naturally low strength to support the load [2].

The model of an elastic layer of finite thickness underlain by a rigid layer is widely used in

${ }^{*}$ Corresponding author.

E-mail: Salman.Nihal.Dawood@phd. uni-szie.hu

\section{AKJournals} determining foundation displacement [3]. Studies conducted by [4-7] and others have served as the basis for practical use of this model. For the vehicle mobility, the load bearing capacity in infinite thickness, half space and homogeneous soil was studied intensively by [8-11] and others researchers. Ageykin [12] proposed a complex load-bearing capacity formula which gives a description for most soils, including soils with finite thickness and hard layer. This 
formula considers the effect of footing dimensions on soil deformation and gives an adequately close description of the complex function $z=f(D)$, where $z$ is the sinkage and $D$ the diameter of a circle equal to penetrometer area. Saakyan [13] suggested the simplest load carrying capacity equation as a function of depth for homogeneous soil derived from the Boussinesq theory of the elastic half-space.

$$
p=k\left(\frac{z}{D}\right)^{n}
$$

where $D$ is the diameter of the indenter, $z$ is the sinkage, $k$ is the load carrying capacity factor.

The load carrying capacity factor $k$ depends on the soil type, density and moisture content. The exponent $\mathrm{n}$ defines the deformation and compaction behaviour of soil under vertical loading. It is mainly affected by the particle size distribution of the soil and moisture content. An extension of the infinite half space to the finite half space exists but is not widely known. In the agricultural soil, because of the tillage process, the load carrying capacities differ at different depths and the load carrying capacity factor $k$ would be correct [1].

Elasticity theory in soil mechanics [14] proposed that excess in vertical stress from a uniformly load applied on the surface diminishes to a depth of about 1.8 times the diameter of the load. In the case of a hard layer, the pressure and stress propagation throughout the soil would have been significantly modified and not diminished.

The aim of this work was to study the influence of the hard layer on the sinkage by modifying the deformation of the soil in Saakyan model as a function of a thickness $(z=$ $f(H))$. So, one soil thickness $(11 \mathrm{~cm})$ with moisture content (10\%) and the initial bulk density of $1.190 \mathrm{~g} / \mathrm{cm}^{3}$ tested to show the effect of the hard layer. Also, two soil thicknesses $(6$ and $18 \mathrm{~cm}$ ) examined with moisture content of $8 \%$ and the initial density of $1.375 \mathrm{~g} / \mathrm{cm}^{3}$ examined to explain the effect of the hard layer in the case of one variable change and two constants. In addition, the load bearing capacity parameters with finite thickness and the transient point from infinite to finite space was studied in this work.

\section{EXPERIMENTAL PROCEDURE}

The work was conducted at the vehicle engineering laboratory at Szent Istvan University (Godollo, Hungary) where the bevameter (plate-sinkage test) was built and constructed to do the experiments. Figure 1 shows the bevameter test setup. It consists of a hydraulic cylinder to apply load. Soil bin has a dimension of 200, 100 and changeable thickness up to $70 \mathrm{~cm}$. A circular plate of $100 \mathrm{~mm}$ is connected to the hydraulic cylinder and it is in contact with the soil on which a known force is applied. Load cell (RSCC, HBM, Germany) with a capacity of 5,000 $\mathrm{kg}$ for measuring the applied vertical load. Linear position transducer (MLO, Festo, USA) with a linear displacement of $360 \mathrm{~mm}$ to measure sinkage. The slider of the linear position transducer is connected to the cylinder rod and they move at the same time. The hydraulic

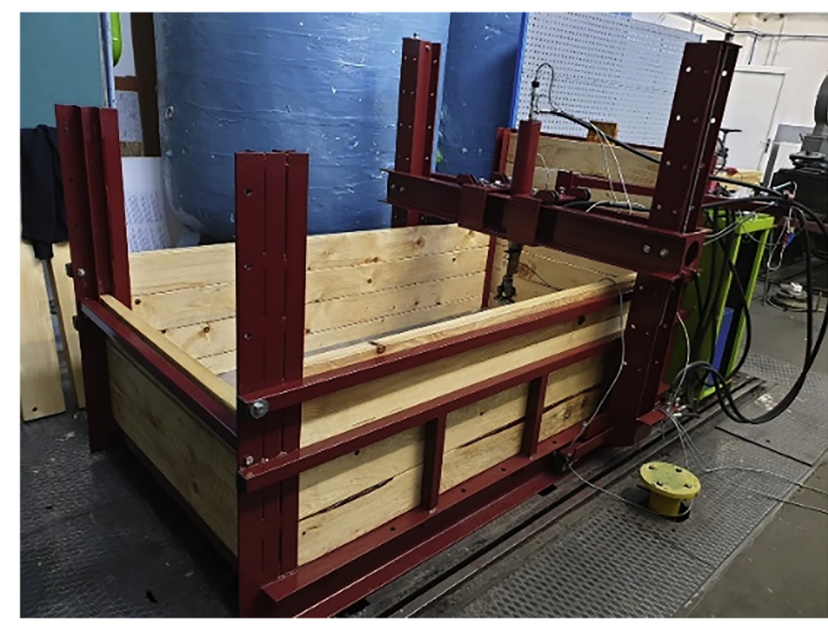

Fig. 1. Bevameter equipment

cylinder is able to move transversely and longitudinally by using rail for testing all the point of soil surface in the soil bin.

Spider8 Data Acquisition System (HBM, Germany) was used to display the values of force and displacement, by transferring the data from the linear position transducer and output load cell to the computer.

The soil was brought from one of the fields that belong to the university. The soil is classified as a sandy loam with a texture analysis of sand (2-0.05 mm), mud (0.05-0.002 $\mathrm{mm}$ ) and clay $(<0.002 \mathrm{~mm})$, which is the same soil that Pillinger [15] and Máthé [16] used in their work. The soil has been filtered to remove the coarse parts like small stone and root of the plants as seen in Fig. 2.

The soil was maintained at approximately $8 \%$ moisture content throughout the tests with an initial bulk density of $1.375 \mathrm{~g} / \mathrm{cm}^{3}$ for the thickness of the soil $(6$ and $18 \mathrm{~cm})$ and thickness of $11 \mathrm{~cm}$, maintained at $10 \%$ moisture content with initial soil density $\left(1.190 \mathrm{~g} / \mathrm{cm}^{3}\right)$. These parameters used to test the relationship of the pressure with the relative sinkage $(z / H)$. To fill the bin with the soil, the soil density and the volume of the bin up to the specific thickness are known, the mass of the soil has been calculated. Thereafter

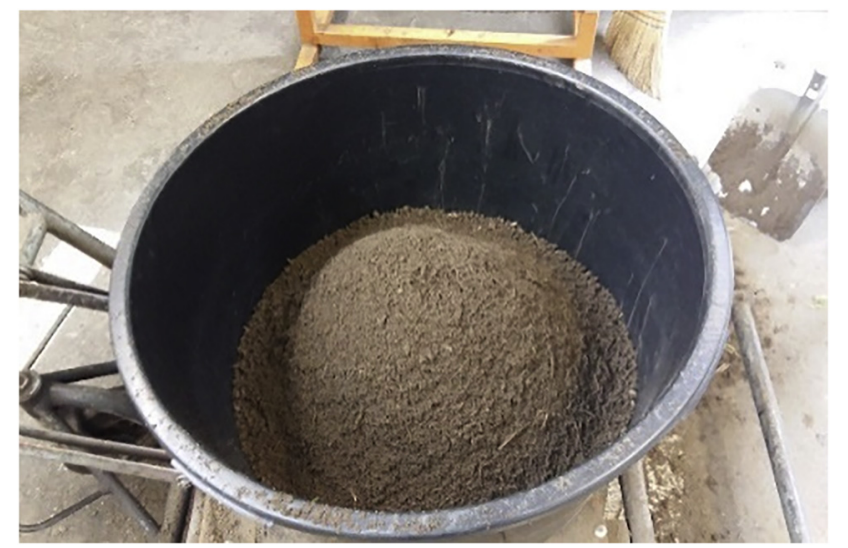

Fig. 2. Purified soil 


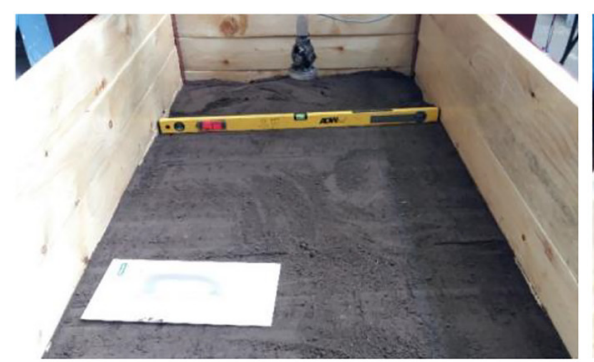

a

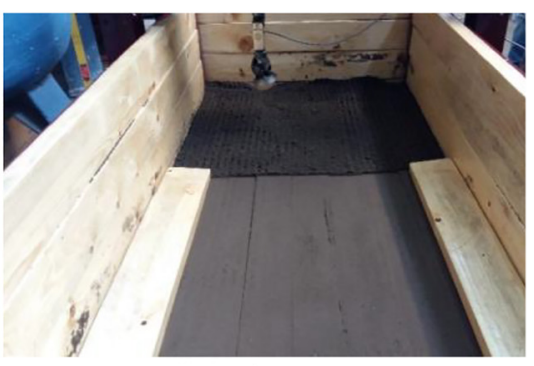

b

Fig. 3. (a) Filling and levelling the soil inside the bin, (b) Pressing the soil surface

the soil was weighed on the scale to the specified mass then discharged into the bin. Leveller was used to level the soil surface; Fig. 3a shows the soil surface with levelling. The soil was compressing gently and uniformly with a large wood plate to the set thickness, Fig. $3 \mathrm{~b}$ shows the soil surface while pressing. The thickness of $11 \mathrm{~cm}$ was achieved by filling one layer without pressing to get loose soil, while the $18 \mathrm{~cm}$ was achieved by filling three layers of soil, each layer of around $39 \mathrm{~mm}$ thickness and each layer was pressed with a wood plate to get more pressed soil, the levelling and pressing procedure applied for each layer. Experiments were carried out at a penetration rate of sinkage plates of $9 \mathrm{~cm} / \mathrm{min}$.

\section{RESULTS AND DISCUSSION}

In each test, the bevameter plate was loaded at multiple locations $(1,2,3,4,5,6,7)$ on the soil surface in the bin, as seen in Figs 4, 5 and 6, which showed approximately repeatable pressure-sinkage measurements. This reveals the

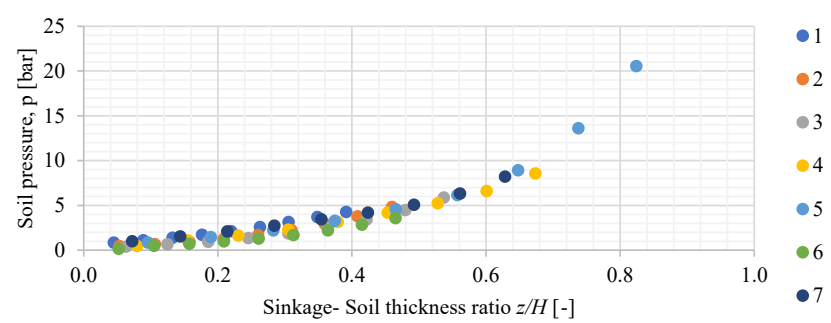

Fig. 4. Pressure-sinkage curves for soil thickness of $6 \mathrm{~cm}$

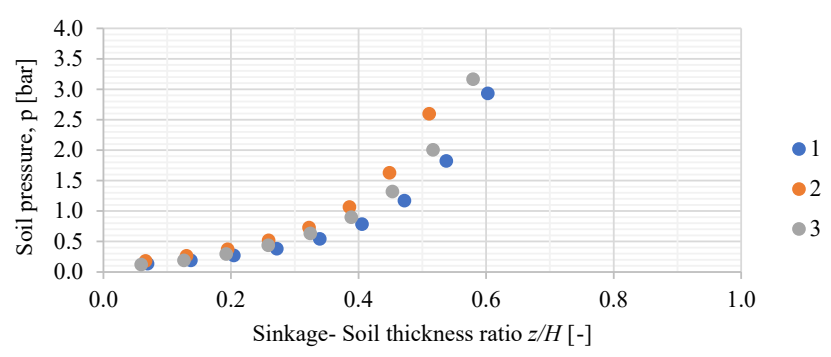

Fig. 5. Pressure-sinkage curves for soil thickness of $11 \mathrm{~cm}$ uniformity and homogeneity of the soil. Table 1 displays the sinkage parameters and the max applied force for each test.

Figure 7 shows the form of the falling of the soil around the test point for each thickness. It reveals the reaction of the firm layer effect clearly on the soil in the case of a thickness of $6 \mathrm{~cm}$ and less in the case of other thicknesses.

Figure 8 shows the logarithmic scale of the soil pressure with respect to relative soil deformation that resulted from the experimental work of applied load on the soil with two thicknesses of pressed soil and one thickness of loose soil. The soil's container's base worked as a hard layer affecting the soil behaviour with all the thicknesses. This resulted in the upper layer behaving as infinite space and the lower layer as finite space. There was no possibility to gain one simple equation as in formula (1) for the measurements, instead of that separate parts of the curves of the measurements can be obtained with formula (1). The transition points from the infinite to finite space can be seen clearly in Fig. 8, for example in the curve of $(11 \mathrm{~cm})$ thickness, line 1 showed the infinite and line 2 shows finite, after that line 3 represents the increase of the soil compaction. This procedure is the same for the two thicknesses $(6$ and $18 \mathrm{~cm}$ ). The pressure

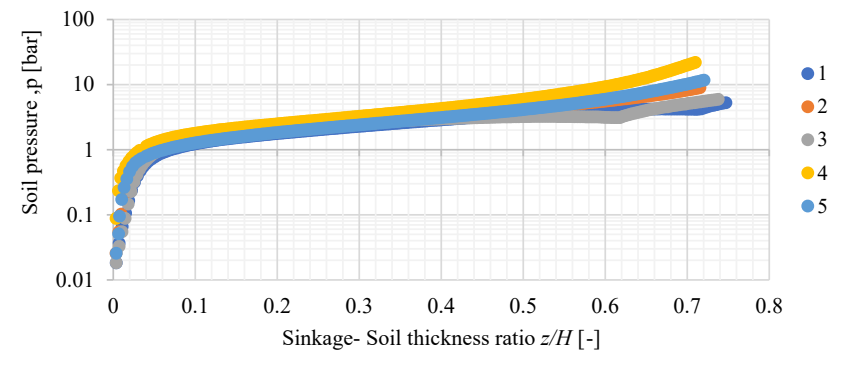

Fig. 6. Pressure-sinkage curves for soil thickness of $18 \mathrm{~cm}$

Table 1. Sinkage parameters

\begin{tabular}{lccc}
\hline $\begin{array}{c}\text { Thickness of } \\
\text { the soil }(\mathrm{cm})\end{array}$ & $\begin{array}{c}\text { Max. sinkage } \\
(\mathrm{mm})\end{array}$ & $\begin{array}{c}\text { Sinkage thickness } \\
\text { ratio, } z / H(-)\end{array}$ & $\begin{array}{c}\text { Max force } \\
(\mathrm{kN})\end{array}$ \\
\hline 6 & 37.47 & 62.46 & 8 \\
11 & 69.60 & 63.27 & 4 \\
18 & 145.28 & 81.02 & 14 \\
\hline
\end{tabular}




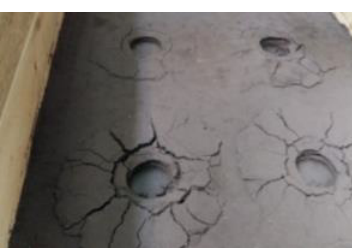

$H=6 \mathrm{~cm}$

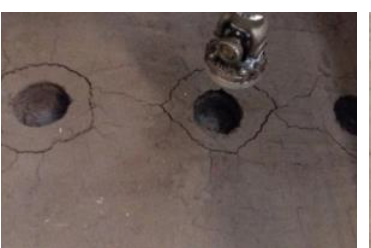

$H=11 \mathrm{~cm}$

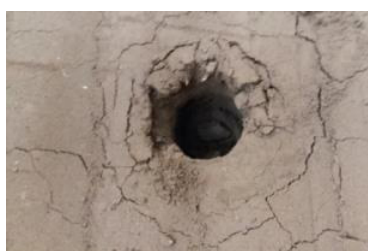

$H=18 \mathrm{~cm}$

Fig. 7. The shape of the soil collapse around the penetration point for each thickness

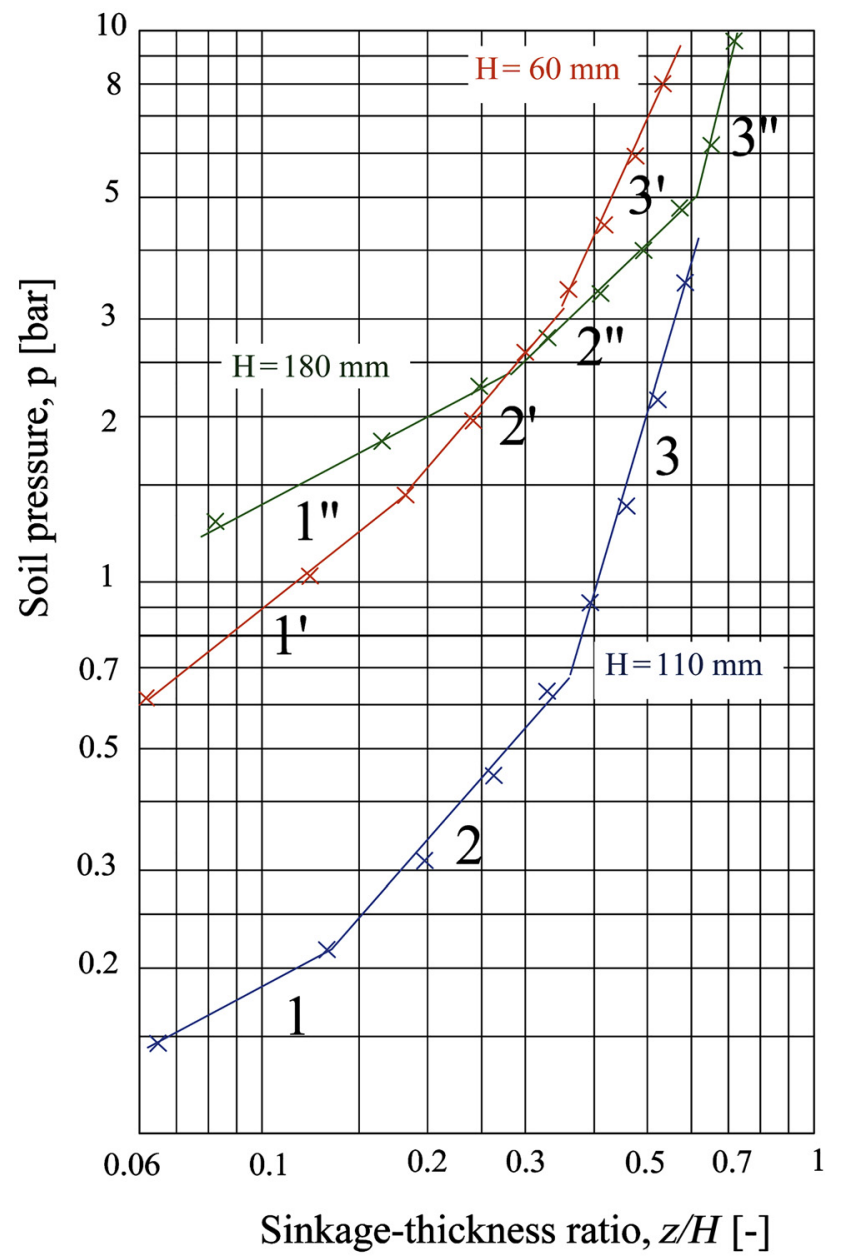

Fig. 8. The logarithmic scale of the relationship between the soil pressure and relative sinkage $z / H$

relative sinkage curves are shown in Fig. 7, which were used to determine the parameters for Eq. (1). Table 2 summarises the results. It can be seen from Table 1 that the value of $\mathrm{n}$ for all the thicknesses increased, which means the deformation of the soil increased. The value of $n$ for the line (3, 3 ' and 3") was high, which means the compaction of the soil increased. Higher differences can clearly be seen in the values of $n$ with a thickness of $11 \mathrm{~cm}$ compared to 6 and $18 \mathrm{~cm}$ because the moisture content was different. The value of load bearing capacity factor $(k)$ also increased for all the thicknesses but increasing the soil thickness $(6$ and $18 \mathrm{~cm}$ ) resulted no bigger difference because it had the same density, however,
Table 2. Model parameters

\begin{tabular}{lccrc}
\hline Soil thickness $[\mathrm{cm}]$ & Line number & $n$ & \multicolumn{1}{c}{$K$} & $R^{2}$ \\
\hline 6 & $1^{\prime}$ & 0.781 & 5.192 & 0.998 \\
& $2^{\prime}$ & 1.192 & 10.915 & 0.995 \\
& $3^{\prime}$ & 2.246 & 32.584 & 0.991 \\
11 & 1 & 0.501 & 0.183 & 1 \\
& 2 & 1.192 & 2.307 & 0.981 \\
& 3 & 3.078 & 16.798 & 0.979 \\
18 & $1^{\prime \prime}$ & 0.532 & 4.714 & 0.998 \\
& $2^{\prime \prime}$ & 0.966 & 8.050 & 0.948 \\
& $3^{\prime \prime}$ & 4.011 & 35.630 & 0.987 \\
\hline
\end{tabular}

for the $11 \mathrm{~cm}$ thickness the difference was more considerable because the density was different.

\section{CONCLUSION}

This paper presented the experimental results of normal bevameter tests. The overall motivation was to determine the affection of the hard layer on the sinkage and to define the relationship of soil pressure and the relative sinkage $z / H$. The experimental results with three thicknesses demonstrated that the upper layer of the soil behaves like infinite space. Then because of the firm layer, the layers underneath behave like finite space and the pressure increases as a result of that. For the loose soil, the transition from infinite to finite space happened at a pressure of $(0.22$ bar $)$. While the other thickness required higher pressure due to the soil being more compressed and the density was being higher. The value of $(n)$ for all the thicknesses increased, which means the deformation of the soil increased. In addition, the reaction of the hard layer affects the soil behaviour which increases the compaction as seen in Fig. 7 for the line $(3,3$ ' and $3^{\prime \prime)}$. It can be clearly seen that the value of $(n)$ differs significantly for the thickness of $11 \mathrm{~cm}$ in comparison with the thicknesses of 6 and $18 \mathrm{~cm}$ because the moisture content was different. The value of load bearing capacity factor $(k)$ also increased for all thicknesses. However, the increase with the soil thicknesses $(6$ and $18 \mathrm{~cm})$ is not notably different. That is because it had the same density. While for the $11 \mathrm{~cm}$ thickness, the difference was more considerable because the density was different. The hard layer modified the soil behaviour and the load-bearing capacity parameters ( $n$ and $k$ ). 


\section{ACKNOWLEDGEMENTS}

This work was supported by the Stipendium Hungaricum Programme and by the Mechanical Engineering Doctoral School, Szent István University, Gödöllö, Hungary.

\section{REFERENCES}

[1] G. Sitkei, G. Pillinger, L. Máthé, L. Gurmai, and P. Kiss, "Methods for generalization of experimental results in terramechanics," $J$. Terramechanics, vol. 81, pp. 23-34, 2019. https://doi.org/10.1016/j. jterra.2018.05.004.

[2] D. L. Antille, D. Ansorge, M. L. Dresser, and R. J. Godwin, "Soil displacement and soil bulk density changes as affected by tire size," Am. Soc. Agric. Biol. Eng., vol. 56, no. 5, pp. 1683-93, 2013. https://doi.org/10.13031/trans.56.9886.

[3] S. G. Kushner, "Stress-strain state of a bed of finite thickness under an arbitrary strip load applied to the surface," Soil Mech. Found. Eng., vol. 35, no. 1, pp. 2-7, 1998. https://doi.org/10.4324/9781315846484.

[4] M. A. Biot, "Effect of certain discontinuities on the pressure distribution in a loaded soil," J. Appl. Phys., vol. 6, no. 12, pp. 367-75, 1935. https://doi.org/10.1063/1.1745279.

[5] H. G. Poulos, "Stresses and displacements in an elastic layer underlain by a rough rigid base," Géotechnique, vol. 17, pp. 378-410, 1967. https://doi.org/10.1680/geot.1967.17.4.378.

[6] I. Sovinc, "Stresses and displacements in a limited layer of uniform thickness, resting on a rigid base, and subjected to an uniformly distributed flexible load of rectangular shape," 5th Int. Conf. Soil Mech. and Found. Eng., pp. 823-7, 1961.

[7] D. M. Milovic and J. P. Tournier, "Stress and displacment due to rigid rectangular foundation on a layer of finite thickness," Soil Found., vol. 13, no. 4, pp. 29-43, 1973. https://doi.org/10.3208/ sandf1972.13.4_29.

[8] M. G. Bekker, Introduction to Terrain-Vehicle Systems: Book, 1st ed., University of Michigan Press, (March 1, 1969), pp. 38-69, 1969.

[9] A. R. Reece, "Principles of soil-vehicle mechanics," Proc. Instit. Mech. Eng., vol. 180, no. 1, pp. 45-66, 1965. https://doi.org/10. 1243/PIME_AUTO_1965_180_009_02.

[10] O. Onafeko and A. R. Reece, "Soil stress and deformation beneath rigid wheels," J. Terramechanics, vol. 59, no. 1, pp. 59-80, 1967. https://doi.org/10.1016/0022-4898(67)90104-8.

[11] V. V. Kacigin and V. V. Guskovt, "The basis of tractor performance theory," J. Terramechanics, vol. 5, no. 3, pp. 43-66, 1968. https://doi.org/10.1016/0022-4898(68)90080-3.

[12] Y. S. Ageykin, "Evaluation of ground deformability with respect to vehicle mobility," J. Terramechanics, vol. 10, no. 1, pp. 105-11, 1973. https://doi.org/10.1016/0022-4898(73)90051-7.

[13] P. Kiss, Some Questions About Energy On Field Vehicles. Doctoral dissertation, Godollo, Szent Istvan University, p. 13, 2001.

[14] M. Budhu, Soil Mechanics Fundamentals: Book, John Wiley \& Sons, p. 157, 2015.

[15] G. Pillinger, Deformation and Damping of Soil under Tire. Doctoral dissertation, Szent Istvan University, p. 31, 2016.

[16] L. Máthé, Analysis of the Motion of Vehicles Running onto Terrain. Doctoral dissertation, Szent Istvan University, p. 74, 2014. 